\title{
Polyvalent therapeutic vaccine for type 2 diabetes mellitus: Immunoinformatics approach to study co-stimulation of cytokines and GLUT1 receptors
}

Syed Aun Muhammad ${ }^{1 *}$, Hiba Ashfaq ${ }^{1}$, Sidra Zafar ${ }^{1}$, Fahad Munir ${ }^{2}$, Muhammad Babar Jamshed ${ }^{3}$, Jake Chen ${ }^{4}$ and Qiyu Zhang ${ }^{5^{*}}$

\begin{abstract}
Background: Type 2 diabetes mellitus (T2DM) is a worldwide disease that have an impact on individuals of all ages causing micro and macro vascular impairments due to hyperglycemic internal environment. For ultimate treatment to cure T2DM, association of diabetes with immune components provides a strong basis for immunotherapies and vaccines developments that could stimulate the immune cells to minimize the insulin resistance and initiate gluconeogenesis through an insulin independent route.
\end{abstract}

Methodology: Immunoinformatics based approach was used to design a polyvalent vaccine for T2DM that involved data accession, antigenicity analysis, T-cell epitopes prediction, conservation and proteasomal evaluation, functional annotation, interactomic and in silico binding affinity analysis.

Results: We found the binding affinity of antigenic peptides with major histocompatibility complex (MHC) Class-l molecules for immune activation to control T2DM. We found 13-epitopes of 9 amino acid residues for multiple alleles of MHC class-I bears significant binding affinity. The downstream signaling resulted by T-cell activation is directly regulated by the molecular weight, amino acid properties and affinity of these epitopes. Each epitope has important percentile rank with significant $A N N I C_{50}$ values. These high score potential epitopes were linked using AAY, EAAAK linkers and HBHA adjuvant to generate T-cell polyvalent vaccine with a molecular weight of $35.6 \mathrm{kDa}$ containing 322 amino acids residues. In silico analysis of polyvalent construct showed the significant binding affinity $(-15.34 \mathrm{Kcal} / \mathrm{mol})$ with MHC Class-I. This interaction would help to understand our hypothesis, potential activation of T-cells and stimulatory factor of cytokines and GLUT1 receptors.

Conclusion: Our system-level immunoinformatics approach is suitable for designing potential polyvalent therapeutic vaccine candidates for T2DM by reducing hyperglycemia and enhancing metabolic activities through the immune system.

\footnotetext{
*Correspondence: aunmuhammad78@yahoo.com; qiyuz@126.com

'Institute of Molecular Biology and Biotechnology, Bahauddin Zakariya University Multan, Multan, Pakistan

${ }^{5}$ Department of Hepatobiliary Surgery, The First Affiliated Hospital of Wenzhou Medical University, Wenzhou 325000, People's Republic of China Full list of author information is available at the end of the article
} 


\section{Background}

Type 2 diabetes mellitus (T2DM), a non-insulin dependent metabolic disorder, is a pandemic disease affecting large set population of the world [1]. It is responsible for $90 \%$ of total diabetic population and sixth prime cause of disability. T2DM is characterized by the inability of pancreatic $\beta$-cells to produce enough insulin resulting hyperglycemia and the inability of insulin to bind with its receptors restrict the absorption of glucose (insulin resistance) into the cells [2,3]. Disease prevalence is increasing for sure due to unknown causes and the lack of therapeutic strategies [4, 5].

Normally, insulin regulates the absorption of glucose through glucose transporter type 4 (GLUT-4) protein channels [6] present in cell membranes. In case of insulin impairment, the absorption of glucose by GLUT-4 doesn't occur, causing T2DM [7]. The glucose transporters (GLUT1 and GLUT4) facilitate glucose transport into cells. GLUT1 is insulinindependent and is widely distributed in different tissues $[8,9]$. Cells need growth factors to facilitate glucose absorption for subsistence and development. Tcell stimulation leads to fast proliferation and differentiation into effector cells that release cytokines and mediate the immunity [10-12].
The non-insulin growth factors such as cytokines including interleukin IL3 and IL7 may absorb the glucose through glucose transporter type 1 (GLUT-1) proteins. These cytokines can trigger the cascade of important signals to promote glucose uptake via different pathways. GLUT1 proteins in response to cytokines released by active immune components facilitate the constitutive, insulin-independent glucose uptake in most of the cells including hematopoietic and muscle cells [13-15].

The progression of T2DM is also associated to abnormal immune responses [16], and therefore the cytokinemediated regulation of GLUT-1 can be thought of playing some significant role in this respect. The metabolic reprogramming is shaped to help definite cell functions [17] and glucose uptake delivers a key metabolic control point through the GLUT family of facilitative glucose transporters.

In this study, we hypothesize the development of potential immunotherapeutic vaccine candidates for the activation and secretion of cytokines (IL-1, IL-3, and IL-7) to facilitate glucose absorption and cure T2DM. The issues related to insulin resistance could be minimized through alternative non-insulin dependent GLUT1 pathway. We predicted the T-cell epitopes and analyzed the in-silico binding affinity with MHC class-I molecules.

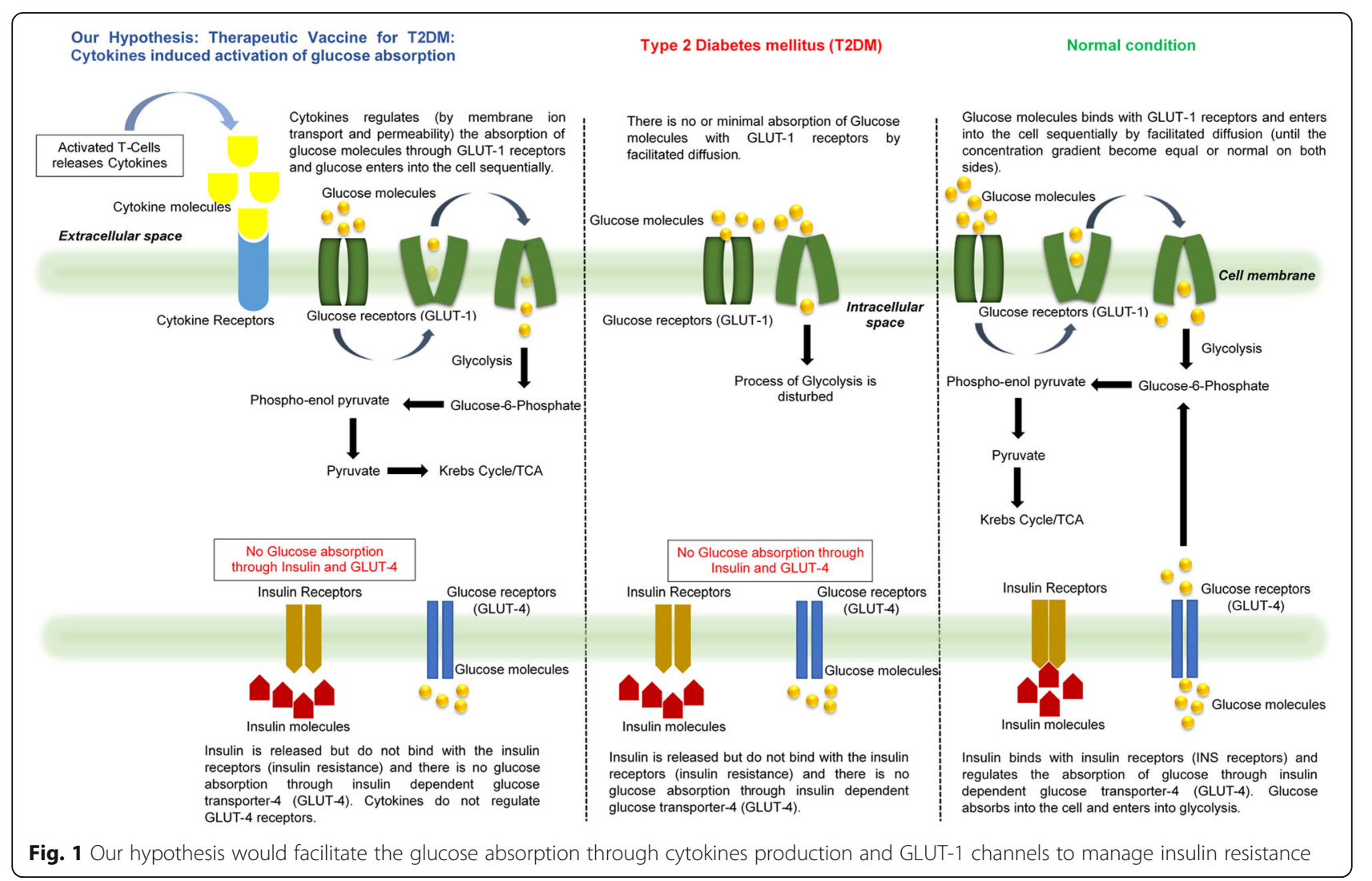


Our vaccine would target the T-cells resulting the secretion of interleukins. Instead of insulin dependent GLUT4 channels, these interleukins open up the GLUT-1 proteins and regulate the glucose absorption. Our hypothesis has been illustrated in Fig. 1. This study would modulate the therapeutic strategies to manage type 2 diabetes mellitus.

\section{Method}

\section{Retrieval of protein data}

The tissue specific (bearing GLUT-1 receptors) protein sequences were retrieved from NCBI and Uniprot databases (Supplementary Table 1). The data covered all information including protein names, gene symbols, Uniprot accession numbers, protein description and sequences. The currently available proteins sequences associated to type 2 diabetes mellitus (Supplementary Table 2) were accessed from diabetic databases. We carried out this study using integrated framework (Fig. 2) by computational tools, databases, online servers and software (Table 1).

\section{Screening of antigenic proteins}

We mapped the non-tissue specific list of diabetic proteins with the entire list of tissue specific proteins using "Compare Two Lists" tool [23] to shortlist the T2DM associated proteins in the relevant tissues. The antigenicity of these shortlisted proteins were determined (based on the significant threshold level > 0.5) using "VaxiJen v2.0" server [47]. To select the robust and effective antigenic proteins, these proteins were further screened and filtered based on the molecular weight (threshold of $>85$

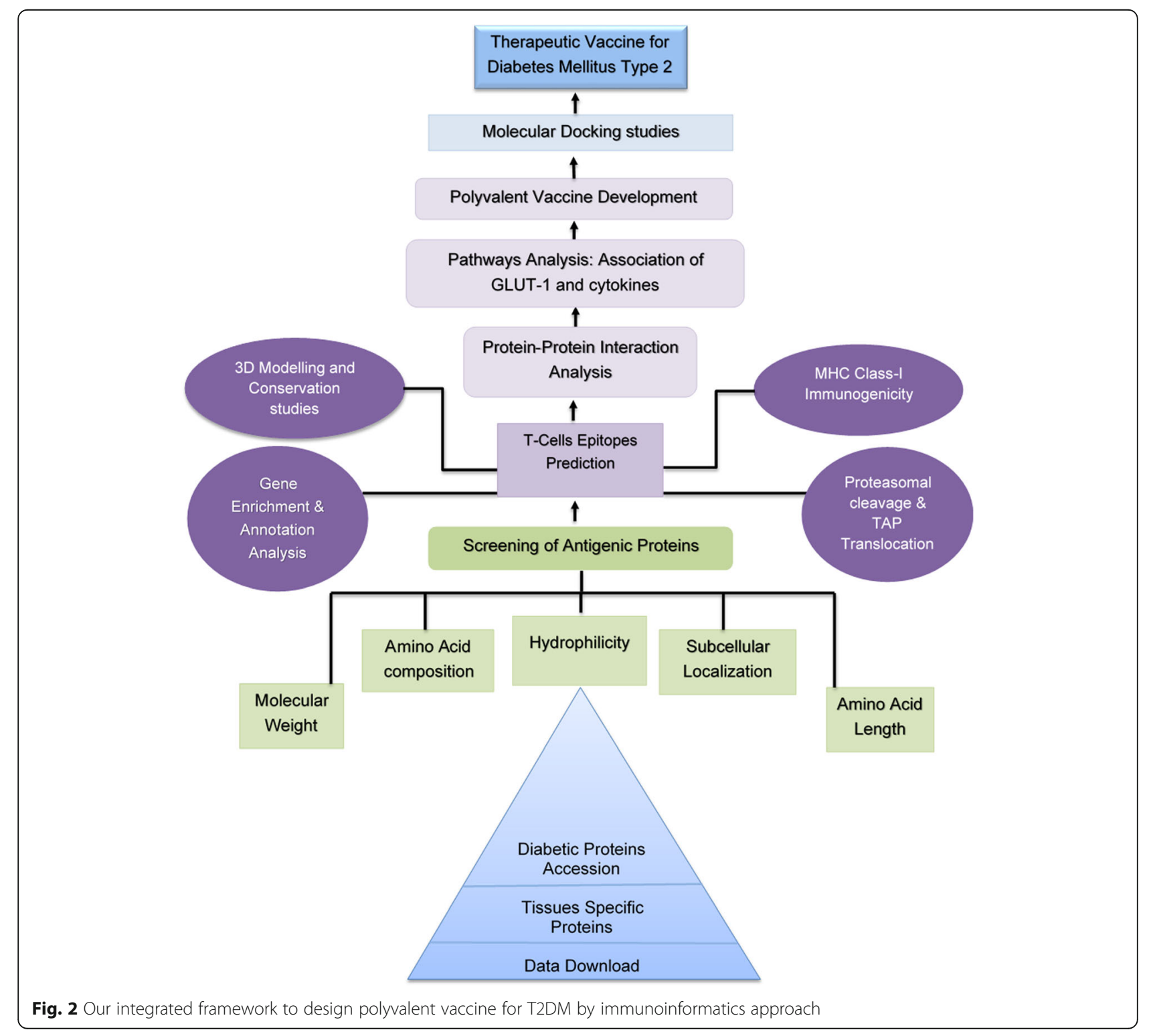


Table 1 Tools, Databases and Software used in this study

\begin{tabular}{|c|c|c|c|}
\hline Database/Tools & Web Link & Purpose & References \\
\hline $\mathrm{NCBI}$ & https://www.ncbi.nlm.nih.gov/ & Accession of Data & - \\
\hline T2D@ZJU & http://pharminfo.zju.edu.cn/t2d & Diabetes associated genes retrieval & [18] \\
\hline DAPD & http://mkarthikeyan.bioinfoau.org/dapd/ & Retrieval of proteins & [19] \\
\hline ToxinPred \& PredSTP & https://webs.iiitd.edu.in/raghava/toxinpred/index.html & Prediction of toxic peptides & {$[20,21]$} \\
\hline UniProt & http://www.uniprot.org & Screening of Diabetic proteins & [22] \\
\hline Compare Two Lists & http://jura.wi.mit.edu/bioc/tools/compare.php & Comparison & {$[23]$.} \\
\hline SPpred & http://crdd.osdd.net:8081/sppred/submit.jsp & Solubility/hydrophilicity determination & - \\
\hline PROTPARAM & http://web.expasy.org/protparam/ & Amino Acid composition & [24] \\
\hline CELLO & http://cello.life.nctu.edu.tw/ & Subcellular Localization Prediction & [25] \\
\hline PROPRED I & http://crdd.osdd.net/raghava/propred1/ & Prediction of T-Cell epitopes & [24] \\
\hline HADDOCK 2.2 & https://haddock.science.uu.nl/ & Docking of epitopes & [26] \\
\hline IEDB (NetChop) & http://tools.iedb.org/netchop/result/ & Proteasomal cleavage prediction & {$[27]$} \\
\hline IEDB & http://tools.iedb.org/conservancy/ & Epitope Conservancy Analysis & {$[28]$} \\
\hline PEPFOLD & http://bioserv.rpbs.univ-paris-diderot.fr/services/PEP-FOLD/ & 3D Modelling of Epitopes & [29] \\
\hline DAVID Tool & https://david.ncifcrf.gov/home.jsp & Functional Annotation & {$[30]$} \\
\hline HAPPI & http://discovery.informatics.uab.edu/HAPPI/ & Interactomic analysis & [31] \\
\hline STRING & https://string-db.org/ & Interactomic analysis & {$[32]$.} \\
\hline Cytoscape & http://www.cytoscape.org/ & Protein-protein interaction & [33] \\
\hline MOE & https://www.chemcomp.com/ & Epitopes binding energy & - \\
\hline ITASSER & https://zhanglab.ccmb.med.umich.edu/l-TASSER/ & 3D Model generation & [34-36] \\
\hline Chimera & https://www.cgl.ucsf.edu/chimera/ & Visualization of proteins & [37] \\
\hline FUNRICH & http://www.funrich.org/ & Gene enrichment analysis & {$[38]$} \\
\hline ERRAT & http://servicesn.mbi.ucla.edu/ERRAT/ & Error in model estimation & [39] \\
\hline QMean & https://swissmodel.expasy.org/qmean/ & Quality of model & {$[40,41]$} \\
\hline Rampage Analysis & http://mordred.bioc.cam.ac.uk/rapper/rampage.php & Protein Quality & [42] \\
\hline 3D Refine & http://sysbio.rnet.missouri.edu/3Drefine/ & Refinement of polyvalent model & [43-45] \\
\hline Antigen Pro & http://scratch.proteomics.ics.uci.edu/ & Antigenicity & {$[46]$} \\
\hline Vaxijen & http://www.ddg-pharmfac.net/vaxijen/VaxiJen/ & Antigenicity & [47-49] \\
\hline AlgPred & http://crdd.osdd.net/raghava/algpred/submission.html & Allergenicity & - \\
\hline Sol Pro & http://scratch.proteomics.ics.uci.edu/explanation.htmI\#SOLpro & Solubility of proteins & {$[46]$} \\
\hline Expasy & http://web.expasy.org/compute_pi/ & Molecular Weight prediction & [24] \\
\hline
\end{tabular}

$\mathrm{kDa}$ ) using Expasy Compute pI/MW tool [24, 50], hydrophilicity using SPpred server, amino acid composition using Expasy ProtParam tool [24] and subcellular localization using CELLO v.2.5: Subcellular Localization Predictor tool [25].

T-cell epitopes prediction and immunogenicity analysis We predicted multi-allelic T-Cells epitopes of selected proteins using ProPred-I online server [24]. This server identified the MHC Class-I regions in the input sequences of selected proteins by applying matrices of all 47 alleles of this class. These epitopes have the potential to target several alleles of MHC Class-I. The multiallelic epitopes-based vaccine has more worth and chance of success as compared to the vaccine that target only one type of allele in the whole population. The proteasomal cleavage sites of these antigenic proteins were predicted using NetChop predictor of IEDB tool [27]. The proteasomal prediction is important to find out the potential immunogenic regions in the selected proteins. We verified the immunogenicity of MHC Class-I epitopes using IEDB server. This tool uses amino acid properties and their position within the peptide to find the immunogenicity of a peptide $\mathrm{MHC}$ (pMHC) complex [27]. 


\section{Conservancy analysis and physicochemical properties prediction}

The conservational analysis of selected epitopes was analyzed using IEDB server [27] to observe the conservancy between epitopes and the proteins. We predicted the physicochemical properties of candidate peptides including half-life, instability index, net charge, peptide toxicity, and hydropathicity using ToxinPred and PredSTP servers [20, 21]. The half-life of peptide varies among species and it is important to determine the half-life of peptides in humans. The stability profile of peptide is indicated by the value of the instability index. The charge of a peptide is $\mathrm{pH}$-dependent. At the isoelectric point, the net charge on protein is zero. The solubility of protein is lowest at its isoelectric point. The hydropathicity analysis provides detail information about individual amino acid that enables us to predict the overall threedimensional structure of a protein from its amino acid sequence. The Support Vector Machine (SVM) model of amino acid composition was used to predict the toxicity profile of peptides.

\section{Modelling of epitopes}

The three-dimensional (3D) structure of peptides is usually helpful to understand its topological description, biological activity and function. The protein structure prediction often offers a suitable alternative to facilitate structure-based studies. 3D models of selected epitopes were generated by using PEP-FOLD [29], I-Tasser [34] and Chimera [37] tools to observe epitopic regions and underlying pattern of amino acids. These tools require amino acid input sequences to build the peptide folds.

\section{Gene enrichment and annotation analysis}

Gene enrichment and annotation analysis of these peptides were performed using FunRich [38] and David tool [30]. The annotation profiles including functional and cluster details were studied.

\section{Protein-protein interaction (PPI) analysis}

We studied PPI network of selected antigenic proteins to carryout system level investigations. The target interactions of selected source proteins were retrieved using STRING database [32]. This database provides the comprehensive detail about the interactions, functions and pathways of sample proteins. The PPI network was constructed by using Cytoscape v3.6.0 software [33].

\section{Pathways analysis}

To study the physiological role of these potential vaccinating proteins, we designed and constructed the integrated, interactive and metabolic network of T2DMrelated proteins and observed the correlation between these pathways. Cellular and signaling pathways were reconstructed from the combined gene signatures using PathVisio3 tool. These proteins were mapped and curated using KEGG (Kyoto Encyclopedia of Genes and Genomes) and WIKI pathways on the basis of literature and database evidence.

\section{Polyvalent vaccine assembly}

Polyvalent vaccine was designed and constructed by linking selected epitopes of MHC Class-I using potential linkers. We used AAY and EAAAK linkers to link 13-epitopes to minimize the undesirable attachment of their ends that might cause change in amino acid arrangement and even the functionality of proteins [51]. To enhance the immunogenicity, the amino acid sequence (159 residues) of the heparin-binding hemagglutinin (HBHA) was used as adjuvant. On both ends of HBHA, EAAAK linkers were used to make it non-reactive [51]. Epitopes cannot be bluntly linked with each other to design a polyvalent vaccine. The arrangement of amino acid sequences is critical and their order is based on their affinity and compatibility with each other. To design the best and compatible construct of selected epitopes, we used the HADDOCK 2.2 server [26] to analyze the binding affinity of these epitopes. Initially, the binding affinity of each epitope was evaluated followed by the combined sequences to shortlist the best construct. The refinement and residues determination were carried out using HADDOCK: Refinement Interface and Cport modules [26] respectively.

\section{Modelling of polyvalent vaccine and quality estimation} The polyvalent vaccine construct was modelled using ITasser server [34]. The input FASTA format of amino acid sequence was used to generate $3 \mathrm{D}$ model. The model was refined using 3D Refine tool. The quality of the model was estimated by Ramachandran plot and quality model energy analysis (QMEAN) score. Ramachandran plot accurately describes the protein conformation and illustrates the favorable regions for backbone dihedral angles against amino acid residues in protein structure. Similarly, QMean score describes the protein quality on the basis of different geometrical aspects of its structure.

\section{In-Silico binding affinity analysis}

The binding affinity of polyvalent vaccine model with MHC class-I molecule was analyzed using Molecular Operating Environment (MOE) software. The MOE software was set at default parameters and the interaction between molecules was visualized. The active binding sites of the MHC molecule was observed and the 
binding interaction between the amino acid residues was assessed based on binding energy.

\section{Results}

\section{Identifying antigenic proteins}

From the list of 2601 diabetic proteins, we identified 13antigenic tissue specific proteins associated with T2DM based on antigenicity, molecular weight, subcellular localization, amino acid composition, length of protein sequence and solubility using successive screening tools (Fig. 3a). These selected extracellular and membrane bound proteins are associated to blood brain barrier, pancreas, muscles, lymphocytes and intestines (Fig. 3b). These proteins like interleukin-32 (IL-32), insulin like growth factor 1 (IGF1), transforming growth factor beta-1 (TGFB1), toll like receptors-3 (TLR3) and ras-related C3 botulinum toxin substrate 1 (RAC1), with their important biological functions including immune modulation, insulin signaling, cell survival, immune components activation and phosphorylation during glucose metabolism (Table 2).

\section{MHC peptide binding and prediction of T-cell epitopes} T-cell epitopes (9-mers in length) of 13-selected proteins were predicted. These MHC class-I specific epitopes are multi-allelic in nature and could target several alleles of MHC Class-I of human population. We determined 13immunogenic T-cell epitopes with significant percentile rank (\% rank: 0.1), MHC Class-I immunogenicity score $(>0.5)$ and multiple alleles hit. These selected T-cell epitopes of 13-proteins as potential candidate antigens have been listed in Table 3.

\section{Proteasomal cleavage and epitope conservation analysis}

We applied NetChop tool to predict proteasomal cleavage that depends upon a neural network. This method identified the $\mathrm{C}$-terminal at cleavage sites with the threshold value of 0.5 to categorize the cleavage and non-cleavage sites. We observed the cleavage (positive predictions) and non-cleavage (negative predictions) sites of antigenic proteins by proteasomes indicating their significant role in antigen presentation to MHC class-I molecule (Fig. 4). The scores of combined predictions of proteasomal cleavage, TAP translocations, and MHC binding shows each peptide intrinsic capacity of being a T-cell epitope.

Epitope conservation analysis of antigenic peptides showed broad coverage and $100 \%$ protein sequence matches. Conservation analysis was performed by IEDB and epitopes were designed by ProPred-I identified the MHC Class-I regions in the input sequences of selected proteins by applying matrices of all 47 alleles of this class. Those epitopes were selected that are present in maximum alleles out of 47 reported alleles of MHC class I. These epitopes have the potential to target several alleles of MHC Class-I. The multi-allelic epitopes-based vaccine has more worth and the chance of success as compared to the vaccine that targets only one type of allele in the whole population. The conserved epitopes have significant ability to provide the effective immune response (Table 4). Most of the predicted epitopes have instability index $<40$ indicating their stability. A good epitope must be stable and stay in the body to activate the immune components. Most of our predicted peptide has a half-life of more than $5 \mathrm{~h}$ and all are non-toxic. SVM score is used to classify either the epitope is toxic or non-toxic based on the threshold value (non-toxic: < 5). Almost all predicted epitopes have an SVM score of less than 5 indicating non-toxicity. Amino acid chains are either hydrophobic or hydrophilic. The lesser value of hydropathicity means the more hydrophilic character of epitopes (Table 5).
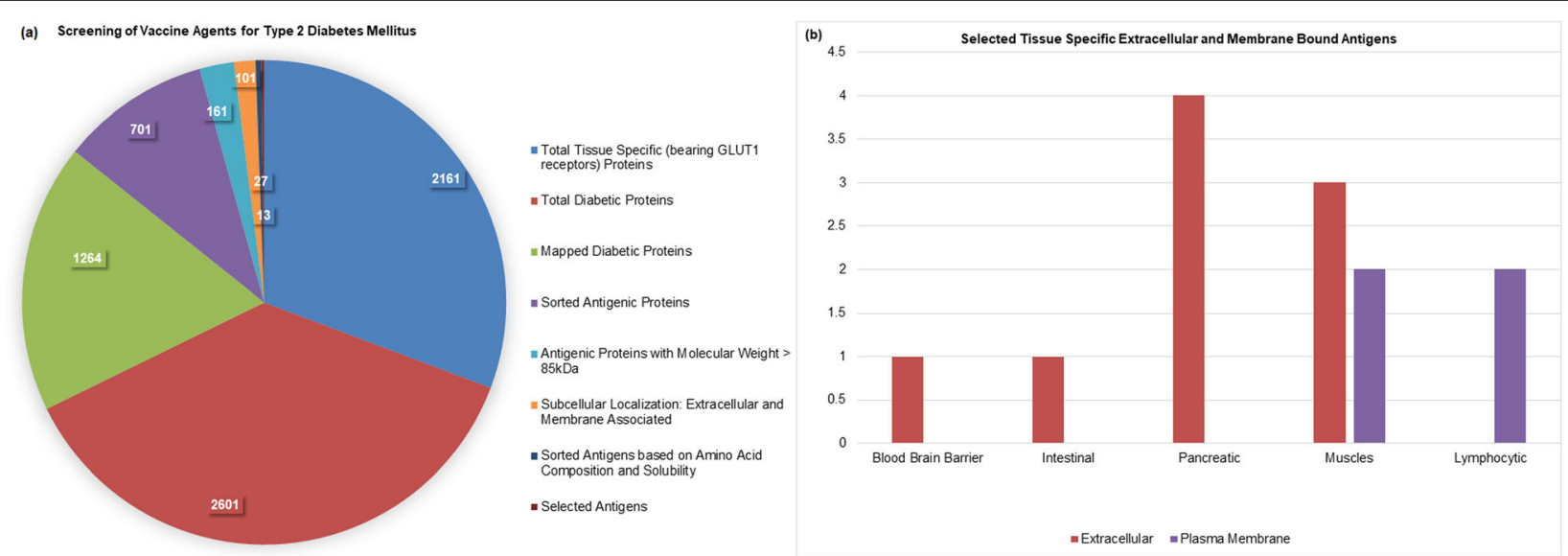

Fig. 3 a Screening of vaccine agents for T2DM using synchronized steps b Distribution of selected extracellularly and membrane bound antigenic proteins in different tissues 
Table 2 List of 13-Potential Antigenic Proteins associated with Type 2 Diabetes Mellitus

\begin{tabular}{|c|c|c|c|c|}
\hline Tissue Name & $\begin{array}{l}\text { Gene } \\
\text { Symbol }\end{array}$ & Uniprot_ID & Protein Names & Subcellular Localization \\
\hline Blood Brain Barrier & RAC1 & RAC1_HUMAN & Ras-related C3 botulinum toxin substrate 1 (Rho family) & Extracellular \\
\hline Intestinal & MMP2 & MMP2_HUMAN & Matrix metallopeptidase 2 (Gelatinase A, 72 kDa gelatinase) & Extracellular \\
\hline Pancreatic & TLR3 & TLR3_HUMAN & Toll-like receptor 3 (CD antigen CD283) & Extracellular \\
\hline Pancreatic & ITGB1 & ITB1_HUMAN & Integrin beta-1 (Fibronectin receptor subunit beta) (Glycoprotein Ila) & Extracellular \\
\hline Pancreatic & LTF & TRFL_HUMAN & Lactotransferrin (Lactoferrin) (Growth-inhibiting protein 12) & Extracellular \\
\hline Pancreatic & IL32 & IL32_HUMAN & $\begin{array}{l}\text { Interleukin-32 (IL-32) (Natural killer cells protein 4) (Tumor necrosis } \\
\text { factor alpha-inducing factor) }\end{array}$ & Extracellular \\
\hline Muscles & LRP6 & LRP6_HUMAN & Low-density lipoprotein receptor-related protein 6 (LRP-6) & Plasma membrane \\
\hline Muscles & LEPR & LEPR_HUMAN & LEPR protein (Fragment) & Extracellular \\
\hline Muscles & TGFB1 & TGFB1_HUMAN & Transforming growth factor, beta 1 (Camurati-Engelmann disease) & Extracellular \\
\hline Muscles & IGF1 & IGF1_HUMAN & Insulin-like growth factor I (IGF-I) (Somatomedin-C) & Extracellular \\
\hline Muscles & HLA-DRA & DRA_HUMAN & HLA-DRA (MHC class II antigen) (major histocompatibility complex & Plasma Membrane \\
\hline Lymphocytic & $A B C B 1$ & A1L471_HUMAN & ATP-binding cassette, (MDR/TAP), member 1 & Plasma Membrane \\
\hline Lymphocytic & TRPM7 & TRPM7_HUMAN & Transient receptor potential cation channel subfamily M member 7 & Plasma Membrane \\
\hline
\end{tabular}

\section{Molecular modeling of epitopes}

We predicted the 3D models of 13-epitopes from input 9-mers amino acid sequences using PEP-FOLD server. In local structure analysis, the probabilities of each Structural Alphabet (SA) on vertical and horizontal axis has been shown (Fig. 5). In heat map Figure, red color codes indicate the helical form of the structure, green presents extended and blue indicates coil conformations. This server found lowest energy conformations with an average RMSD of $2.1 \AA$.

\section{Functional annotation and gene enrichment analysis}

The functional annotation and enrichment of the T2DM associated proteins were analyzed using DAVID and FunRich tools. The functional annotation identifies protein functional domains, disease associations, protein-protein interactions and biological pathways. This cluster analysis showed that these proteins are significantly associated with cell-cell communication, glycosylation, cell surface responses and cell proliferation regulation (Fig. 6a). The biological role of these potential antigenic proteins has been importantly seen in immune cell migration, wound healing, cell mobility, cell communication, anti-apoptosis and lipid metabolism. Their transcription factors involve NKX2-1, ELF1. ZNF513, ZNF238, GLI1 and IRF1 with significant $p$ values $(p<0.05)$ expressed in different tissues (Fig. 6b).

\section{Protein-protein interaction analysis}

To understand and analyze the topology and functional annotation of protein-protein interaction (PPI) of

Table 3 Predicted T-Cell Epitopes (antigenic and immunogenic) of selected proteins

\begin{tabular}{|c|c|c|c|c|c|c|c|}
\hline UNIPROT_ID & Gene Symbol & Molecular Mass (KDa) & T-Cell Epitopes & Peptide Position & No. of Alleles & Antigenicity & MHC Class-I Immunogenicity \\
\hline RAC1_HUMAN & RAC1 & 23 & FDEAIRAVL & 188 & 10 & 0.567 & 0.30733 \\
\hline MMP2_HUMAN & MMP2 & 74 & LVATFWPEL & 508 & 10 & 0.6217 & 0.42341 \\
\hline TLR3_HUMAN & TLR3 & 104 & GCFHAIGRL & 215 & 14 & 0.528 & 0.29277 \\
\hline ITB1_HUMAN & ITGB1 & 88 & TGPDIIPIV & 725 & 7 & 0.9421 & 0.342 \\
\hline TRFL_HUMAN & LTF & 78 & GYTGAFRCL & 546 & 7 & 1.2559 & 0.20718 \\
\hline IL32_HUMAN & IL32 & 27 & LQTWWHGVL & 165 & 10 & 1.0906 & 0.53436 \\
\hline LRP6_HUMAN & LRP6 & 180 & LDQPRAIAL & 137 & 10 & 1.6709 & 0.17365 \\
\hline LEPR_HUMAN & LEPR & 75 & MWIRINHSL & 511 & 10 & 0.6983 & 0.14943 \\
\hline TGFB1_HUMAN & TGFB1 & 44 & LYIDFRKDL & 298 & 10 & 0.6744 & 0.0592 \\
\hline IGF1_HUMAN & IGF1 & 22 & QKEGTEASL & 161 & 2 & 1.1216 & 0.13501 \\
\hline DRA_HUMAN & HLA-DRA & 29 & NVPPEVTVL & 109 & 11 & 0.5111 & 0.17848 \\
\hline A1L471_HUMAN & $\mathrm{ABCB} 1$ & 141 & LLERFYDPL & 1083 & 13 & 1.3167 & 0.20734 \\
\hline TRPM7_HUMAN & TRPM7 & 213 & KQTEEGGNL & 330 & 10 & 1.6003 & 0.26757 \\
\hline
\end{tabular}




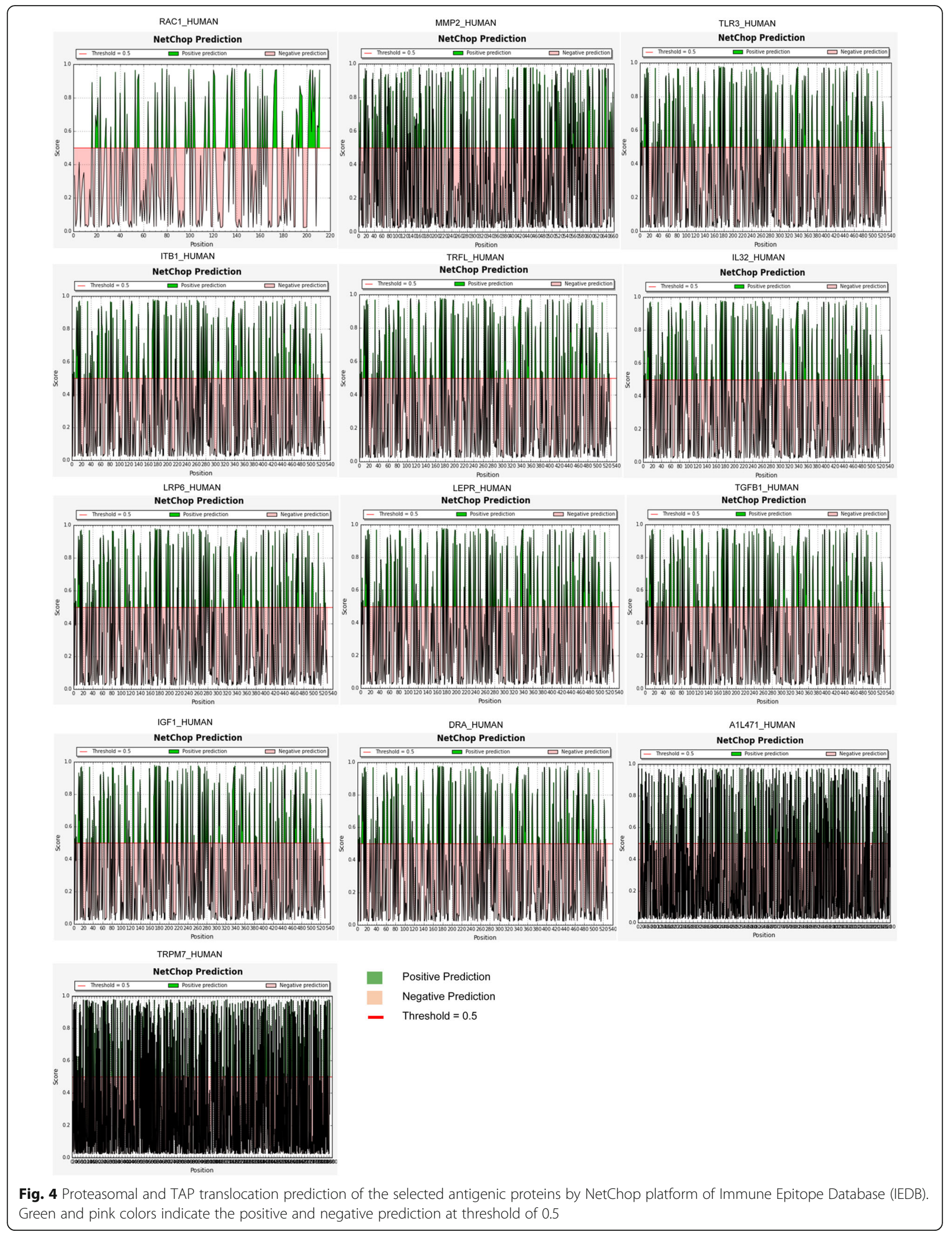


Table 4 T-Cell Epitopes conservation analysis

\begin{tabular}{lllllll}
\hline Epitope \# & Epitope Name & Epitope Sequence & Epitope Length & $\begin{array}{l}\text { Sequence Similarity } \\
<=100 \%\end{array}$ & Minimum Identity & Maximum Identity \\
\hline 1 & ws-separated-0 & FDEAIRAVL & 9 & $100.00 \%(1 / 1)$ & $100.00 \%$ & $100.00 \%$ \\
2 & ws-separated-1 & LVATFWPEL & 9 & $100.00 \%(1 / 1)$ & $100.00 \%$ & $100.00 \%$ \\
3 & ws-separated-2 & GCFHAIGRL & 9 & $100.00 \%(1 / 1)$ & $100.00 \%$ & $100.00 \%$ \\
4 & ws-separated-3 & TGPDIIPIV & 9 & $100.00 \%(1 / 1)$ & $100.00 \%$ & $100.00 \%$ \\
5 & ws-separated-4 & GYTGAFRCL & 9 & $100.00 \%(1 / 1)$ & $100.00 \%$ & $100.00 \%$ \\
6 & ws-separated-5 & LQTWWHGVL & 9 & $100.00 \%(1 / 1)$ & $100.00 \%$ & $100.00 \%$ \\
7 & ws-separated-6 & LDQPRAIAL & 9 & $100.00 \%(1 / 1)$ & $100.00 \%$ & $100.00 \%$ \\
8 & ws-separated-7 & MWIRINHSL & 9 & $100.00 \%(1 / 1)$ & $100.00 \%$ & $100.00 \%$ \\
9 & ws-separated-8 & LYIDFRKDL & 9 & $100.00 \%(1 / 1)$ & $100.00 \%$ & $100.00 \%$ \\
10 & ws-separated-9 & QKEGTEASL & 9 & $100.00 \%(1 / 1)$ & $100.00 \%$ & $100.00 \%$ \\
11 & ws-separated-10 & NVPPEVTVL & 9 & $100.00 \%(1 / 1)$ & $100.00 \%$ & $100.00 \%$ \\
12 & ws-separated-11 & LLERFYDPL & 9 & $100.00 \%(1 / 1)$ & $100.00 \%$ & $100.00 \%$ \\
\hline
\end{tabular}

T2DM-antigenic proteins, the PPI network was constructed. The entire network contained high scoring interaction partners (confidence score: >0.9). The main component of this network contained 448 nodes and 484 edges (nodes represent proteins and edges represent interaction). This interaction network was largely segregated into three neighborhoods: orange nodes indicate the potential vaccine candidate proteins; turquoise nodes represent the proteins that are directly involved in insulin resistance while the pink nodes are other functional proteins. The topological analysis revealed the direct interaction of these antigenic proteins with the target proteins involved in apoptosis, aging, cell division, metabolism, glucose transportation, transcriptional factors activation and
T-cell stimulation. Of these proteins, IGF1 (IGF1_ HUMAN) is principally interacting with INSR (facilitates the action of insulin), FOXO1 (metabolic regulation under stress conditions), STAT3 (involved in signal transduction and cellular reactions to interleukins) PK3CA (initiates cascades of cell growth, motility, survival and proliferation pathways), AKT1 (regulates cell cycle, angiogenesis and metabolic processes), TNFA (anti-tumor activities and cell differentiation), SOCS3 (negatively regulates cytokine signaling) and IL-6 (immune components differentiation and critical immune responses). In the same way, TLR3 (TLR3_HUMAN) is interrelating with IKKB (controls the production of immune mediators and provides security against apoptosis), NFKB1 (final

Table 5 Physicochemical properties of Predicted T-Cell epitopes

\begin{tabular}{|c|c|c|c|c|c|c|c|}
\hline Uniprot ID & Peptide Sequence & SVM Score & Prediction & Hydropathicity & Charge & Half-Life (Hours) & Instability Index \\
\hline RAC1_HUMAN & FDEAIRAVL & -0.87 & Non-Toxin & 0.82 & -1 & 1 & 22.6 \\
\hline MMP2_HUMAN & LVATFWPEL & -1.22 & Non-Toxin & 1.08 & -1 & 5.5 & 41.91 \\
\hline TLR3_HUMAN & GCFHAIGRL & -0.4 & Non-Toxin & 0.77 & 1.5 & 30 & 8.89 \\
\hline ITB1_HUMAN & TGPDIIPIV & -0.52 & Non-Toxin & 1.1 & -1 & 7.2 & -21.56 \\
\hline TRFL_HUMAN & GYTGAFRCL & -0.62 & Non-Toxin & 0.4 & 1 & 30 & -7.44 \\
\hline IL32_HUMAN & LQTWWHGVL & -1.31 & Non-Toxin & 0.24 & 0.5 & 5.5 & 43.2 \\
\hline LRP6_HUMAN & LDQPRAIAL & -1.32 & Non-Toxin & 0.29 & 0 & 5.5 & 21.91 \\
\hline LEPR_HUMAN & MWIRINHSL & -0.55 & Non-Toxin & 0.2 & 1.5 & 30 & 8.89 \\
\hline TGFB1_HUMAN & LYIDFRKDL & -1.01 & Non-Toxin & -0.2 & 0 & 5.5 & 0.51 \\
\hline IGF1_HUMAN & QKEGTEASL & -0.81 & Non-Toxin & -1.19 & -1 & 0.8 & 20.86 \\
\hline DRA_HUMAN & NVPPEVTVL & -1.14 & Non-Toxin & 0.61 & -1 & 1.4 & 61.57 \\
\hline A1L471_HUMAN & LLERFYDPL & -1.17 & Non-Toxin & -0.02 & -1 & 5.5 & 71.42 \\
\hline TRPM7_HUMAN & KQTEEGGNL & -0.84 & Non-Toxin & -1.73 & -1 & 1.3 & 97.1 \\
\hline
\end{tabular}


product of many signal transduction pathways stimulated by inflammation, apoptosis and cell growth) and LRP6 (LRP6_HUMAN) interacts with GSK3B (regulator of glucose homeostasis) (Fig. 7). Such interaction of antigenic proteins makes them effective to regulate the immune responses and metabolic pathways.

\section{Pathways analysis}

The pathways modeling showed that several pathways are involved in T2DM- pathophysiology and they are connected with our core vaccinating proteins. This analysis indicated the association of antigenic protein with immune system and cellular signaling mechanism. Besides insulin-signaling and insulin-resistance pathways, the others are AMPK signaling, JAK/STAT pathway,
FOXO signaling, P13K-AKT signaling, and WNT pathways are associated to our potential antigenic proteins and responsible for the activation of immune components and GLUT-1 receptors to regulate T2DM. It was found that some proteins like RAC1_Human, IGF1_Human, ITB1_Human were associated with the activation of P13K-AKT pathway which is the main regulator of many cellular processes like cell growth, survival and glucose metabolism. In insulin resistance, the FOXO signaling pathway activates GLUT-1 and inhibition of GLUT-4 by IKKB. The immune-regulatory mechanism and increased production of cytokines is associated with the activation of JAK/STAT pathway and GLUT-1 receptors to control glucose metabolism and T2DM (Fig. 8).

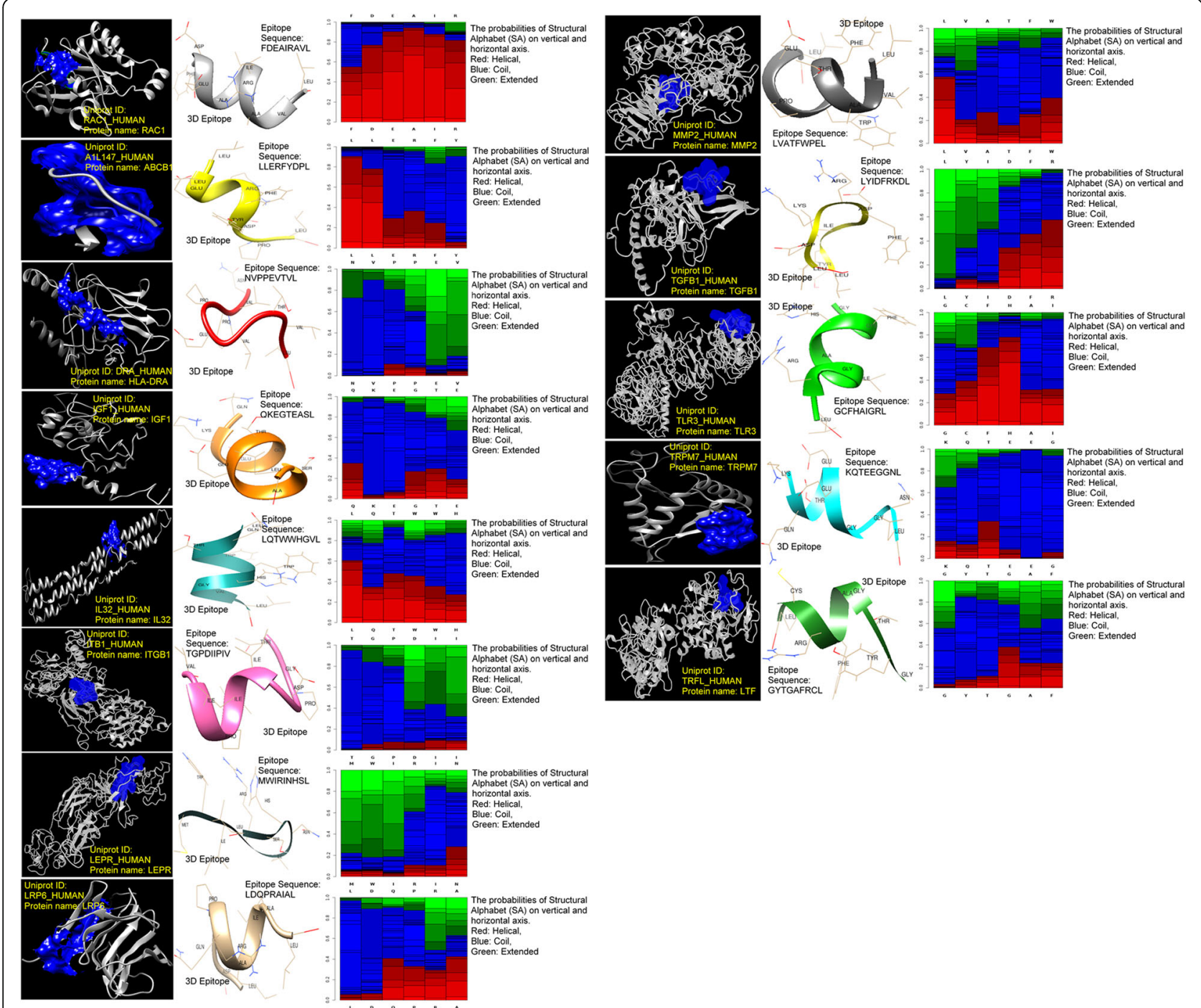

Fig. 5 Generation of 3D models of selected epitopes using I PEPFOLD and Chimera tools. Heats maps designed by PEPFOLD show probabilities of structural alphabet (SA) on horizontal and vertical axis. Red: Helical, Blue: Coil and Green: Extended 


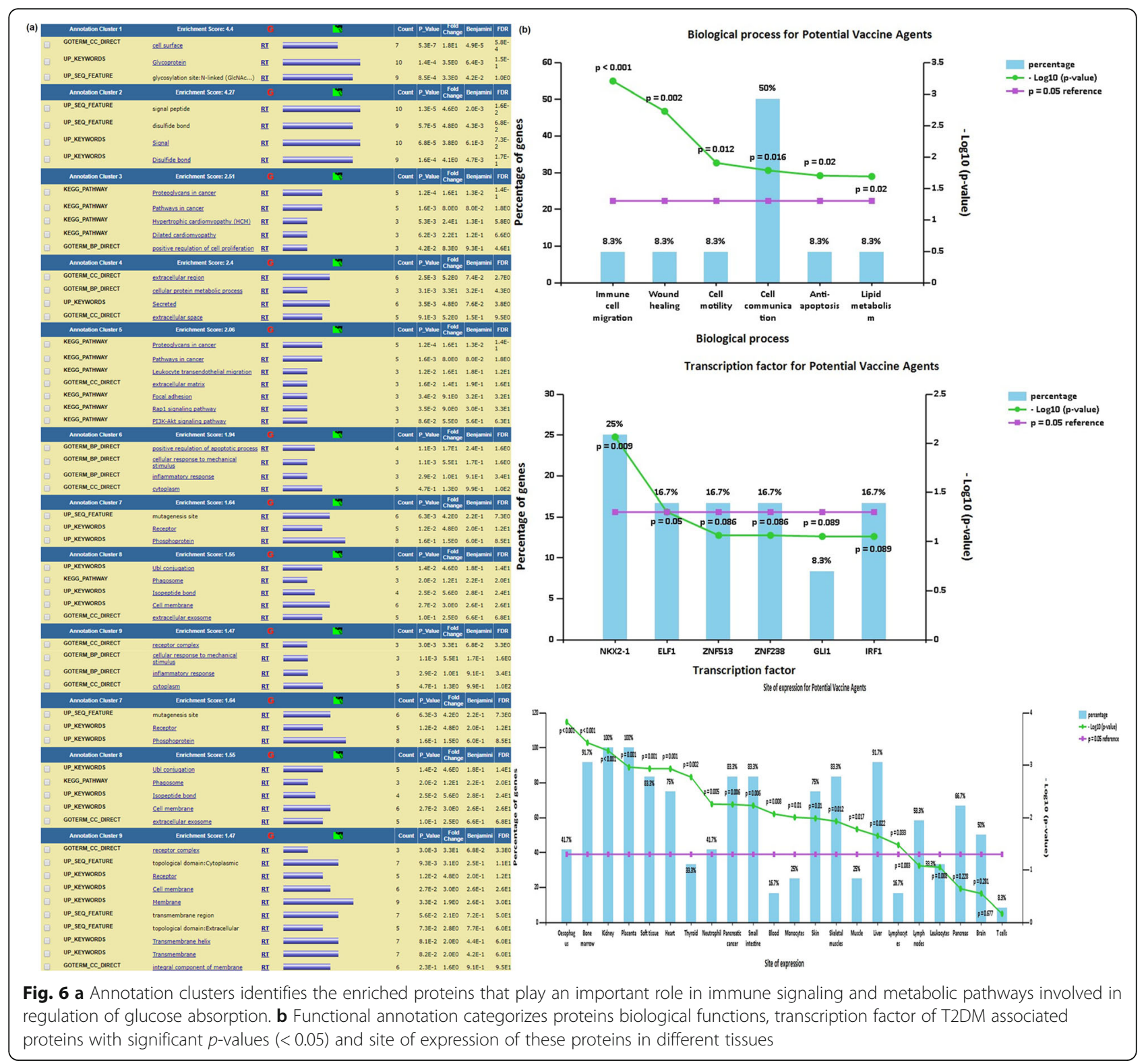

\section{Polyvalent vaccine construct}

For the construction of final vaccine construct, predicted T-cell epitopes were linked to each other with help of suitable and flexible AAY linkers. HBHA (1-159 residues) as adjuvant was added at $\mathrm{N}$-terminals of final constructs with the help of EAAAK linker (Fig. 9a). After adding linkers and adjuvant, the final construct contained 322 amino acid residues with the molecular weight of $35.6 \mathrm{kDa}$ and 3D-model was generated (Fig. 9b). Our polyvalent epitope model showed significant antigenicity (> 0.5 ) determined by Vaxijen server. Analysis of Ramachandran plots indicated that $68.8 \%$ residues of polyvalent protein model (alpha-helices) were in the most favored regions with the $98 \%$ expectation while $2 \%$ in the allowed region. The Ramachandran plot is demonstrating low energy conformations for $\phi$ (phi) and (psi) angles of the model. The graphical representation shows the local backbone conformation of each residue and more than $68 \%$ residues are in favorable region (Fig. 9c). The model was refined and the quality of the construct was estimated by QMEAN score (-15.9) and C-score (-3.62) (Fig. 9d).

\section{Molecular docking: MHC class-I and epitope binding analysis}

We analyzed the binding affinity of polyvalent vaccine construct with MHC class-I molecule using MOE software. The lowest binding energies confirmed the optimum binding patterns between these molecules. 
The interaction of poly-epitopes (ligand) and MHC class-I (target) have been shown in Fig. 10a. We found the following binding energy of polyvalent construct with MHC class-I molecule: - $15.34 \mathrm{Kcal} / \mathrm{mole}$ (Illustration Table of Fig. 10a). It has been observed that polyvalent interacted with ARG, PRO, GLU, TRP, ASP, GLY, THR, LYS, ALA, PHE, TYR, GLN, MET, HIS and LEU amino acid residues of MHC class-I molecule (Fig. 10b). This interaction would prove that our polyvalent would be effective therapeutic vaccine candidate for T2DM.

\section{Discussion}

Type 2 diabetes mellitus is a metabolic complex disease caused by several factors that is characterized by relative lack of obesity, insulin, insulin resistance, and high blood sugar $[52,53]$. Although new therapies and management protocols to cure T2DM are being introduced, still the exact causes and effective treatment is imprecise. Currently, we are using different drug molecules to maintain blood glucose level and cure T2DM [54, 55]. These medications only minimize the symptoms of hyperglycemia and provide short term control. As a result, the drug resistance is developed in most of the diabetic patients and in the while, disease progress so fast that drugs alone cannot encounter it [56].

The current study signifies the importance of immunotherapies and vaccine development to modify the therapeutic strategies. Therapeutic vaccines could be effective to manage T2DM [57] as immune components have been found interactive with glucose transporter proteins [58].

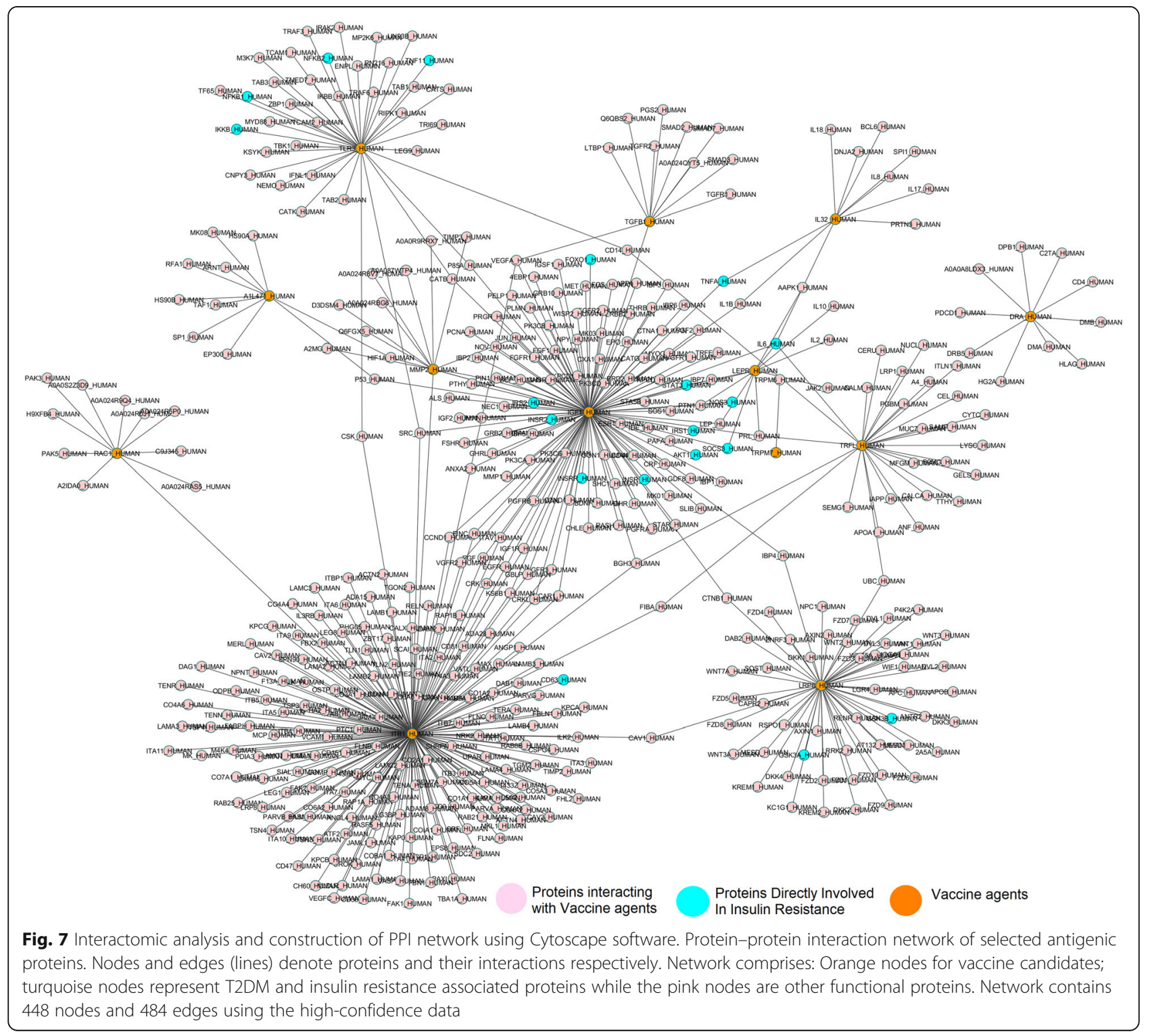




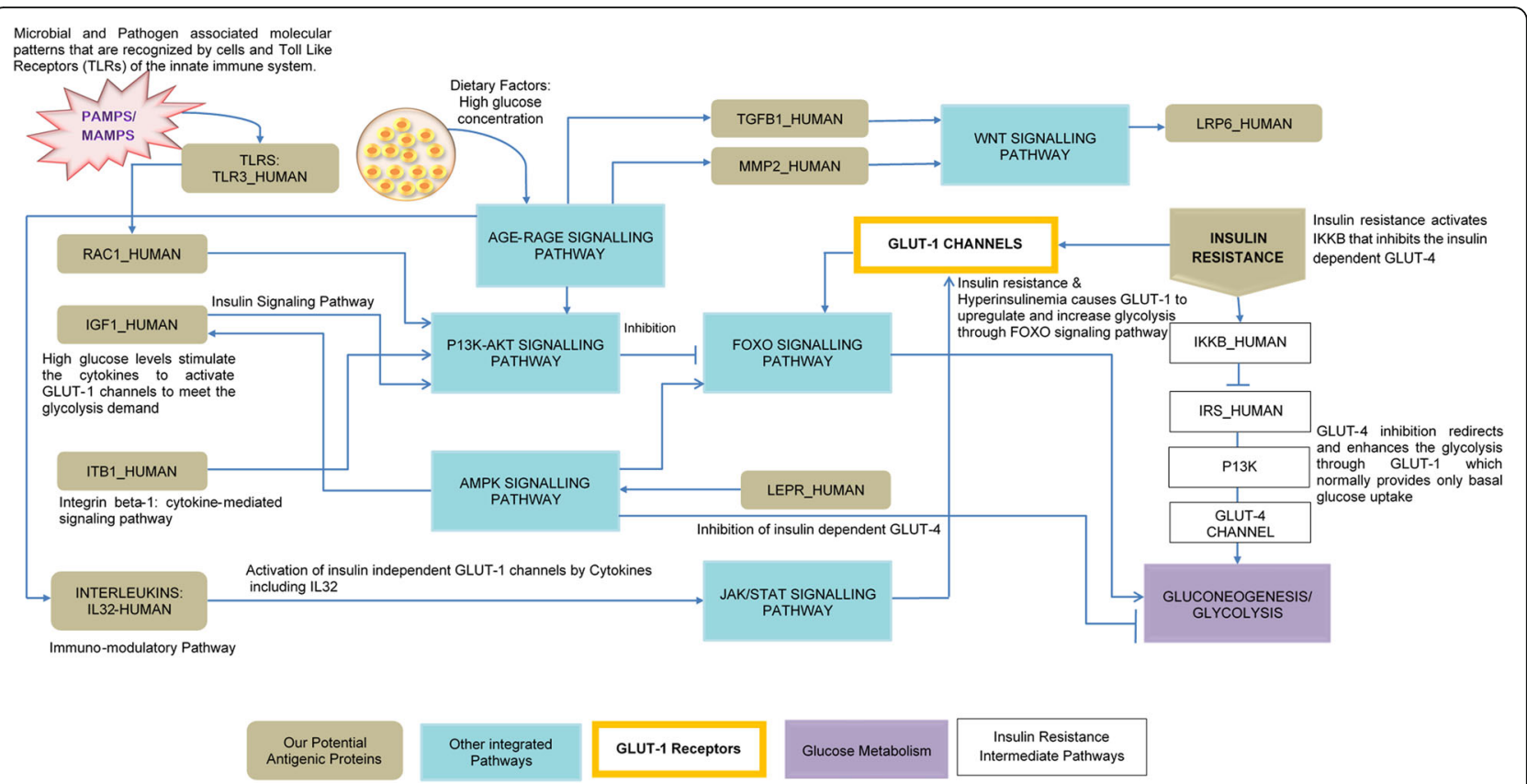

Fig. 8 Pathway analysis indicates the association of our selected antigenic proteins with T2DM related vital pathways, immune signaling system and GLUT-1 receptors

It has been observed that the blood serum cytokines level elevates in diabetic conditions and in turn cytokines opens up the insulin independent glucose transporter channels and cells absorb the glucose [59]. The significant association of interleukin-1 $\beta$ (IL-1 $\beta$ ) with T2DM is reported [53] and the role of antibodies has been studied in diabetic conditions [60].

The evidences about the association of GLUT-1 with immune components are available. It has been revealed that macrophages critically require GLUT-1 for their inflammatory response [61]. Also, the lymphocytes functioning demands high levels of energy that is assisted by GLUT-1 and in turn the expression of GLUT-1 remarkably increases with the increase of immune cells activation [17]. CD4 T-cells and T-effector cells also depends on GLUT-1 for their survival and programming regarding glucose metabolism and the GLUT-1 deficiency causes impairment of both glycolysis and $\mathrm{T}$ cells survival [15]. IL3 has reported to be involved in the trafficking and recycling of GLUT-1 intracellularly and controlling its expression on the cell surface, thus, maintaining the glucose uptake [62]. Cytokines like IL-1 $\beta$ enhances the expression of GLUT-1 and increase the glucose uptake in human articular chondrocytes [63].

Cytokines have also been known to affect and upregulate the GLUT-1 expression significantly by increasing the nitric oxide production levels [64]. Cytokines inhibit the tyrosine kinase activity which downregulates the insulin dependent GLUT-4 and upregulates the expression of insulin independent GLUT-1 [65]. CD28 alone as well as by secreting other immune mediators increases the GLUT-1 induction considerably [66]. TNFA (Tumor Necrosis Factor Alpha) has a cause and effect bond with GLUT-1 and plays a key role in the stabilization of GLUT-1 [67]. Similarly, stimulation of CD46 in CD4 T cells of humans causes the elevated expression of GLUT-1 on cells surfaces [68]. Numerous methods and databases for developing vaccines or immunotherapy against various pathogenic diseases have been developed over the last 20 years. T-cell epitope prediction methods that include indirect techniques such as Major Histocompatibility Complex prediction and transporterassociated protein binders [69]. Endogenous proteins may promote the hypercreativity and autoimmune reactions, however few studies showed that predicted epitopes of endogenous proteins exhibited significant, safe and effective results in animals. Recently, the vaccines for metabolic diseases have made considerable progress, particularly in the treatment of dyslipidemia, atherosclerosis, diabetes mellitus and hypertension, but comprehensive studies are required before any clinical applications [70]. Since T2DM is a multifactorial disorder, T2DM therapeutic-vaccine has been designed to predict obesity protein antigens [71]. Such vaccine targets include adipose tissue antigens, somatostatin, glucose-dependent insulinotropic polypeptide (GIP), and ghrelin [71]. In the studies of Zhang et al., 2018 and Zha et al., 2016 reported that cytokine L- $1 ß$ is a key proinflammatory substance in T2DM pathogenesis and has shown a reduction in weight gain, improved glucose tolerance 


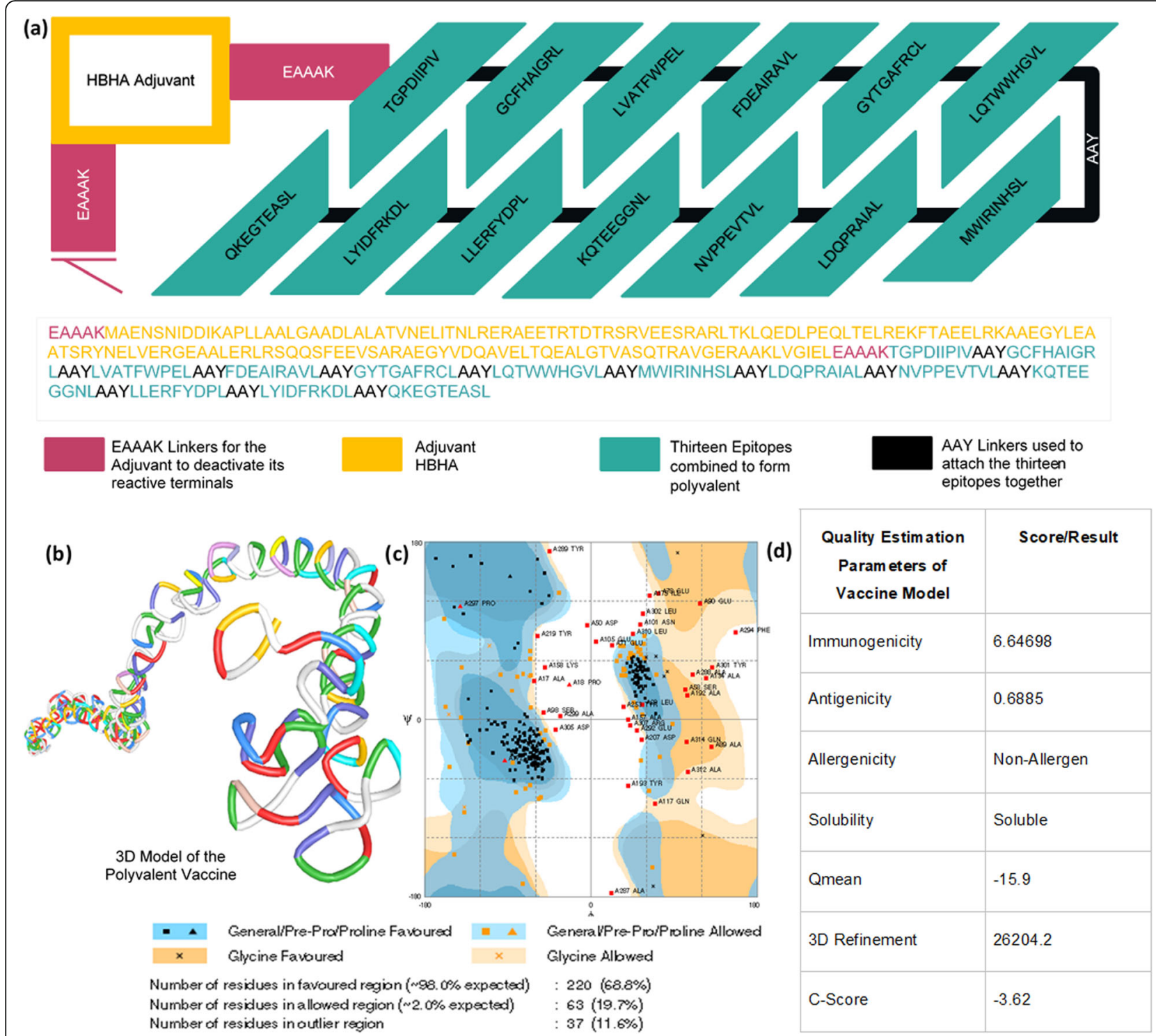

Fig. 9 a Complete sequence of polyvalent vaccine showing the 13 epitopes joined by proper linkers AAY and the suitable adjuvant $H B H A$ at the start, bordered by EAAAK linkers $\mathbf{b}$ generated polyvalent 3-D model $\mathbf{c}$ Ramchandaran Plot for quality estimation and configuration $\mathbf{d}$ Quality refinement and other quality parameters of polyvalent protein model

and insulin sensitivity, and a lower $\beta$-cell loss in their vaccine with predicted peptide epitopes [55, 72]. Similarly, in phase I/II clinical trials vaccine Hil1bQb targeting IL-1 $\beta$ was found safe and well-tolerant [73]. Dipeptidyl peptidase 4 (DPP4) has been studied as an inhibitor of the glucagon-like peptide-1 (GLP-1) glucosedependent insulinotropic peptide (GLP) [74], a therapeutic vaccine against DPP4 that has shown important, safe and successful results in the control of glucose levels in the mouse using GLP-1 [75]. In-silico method for the prediction of antigenic peptides and polyvalent construction could be used to develop vaccines for other human diseases. Molecular docking analysis of the refined vaccine structure with different $\mathrm{MHC}$ molecules and human immune TLR-2 receptor proved significant interaction [76]. In this case, the sequences of those proteins would be required against which we have to design a vaccine. This strategy could be effectively applied for the development of polyvalent vaccine candidates for other diseases specifically cancer and autoimmune diseases.

\section{Conclusion}

This study focused to design potential T-cell polyepitopes to simulate the immune components to provoke glucose transporters to control hyperglycemia. Our 


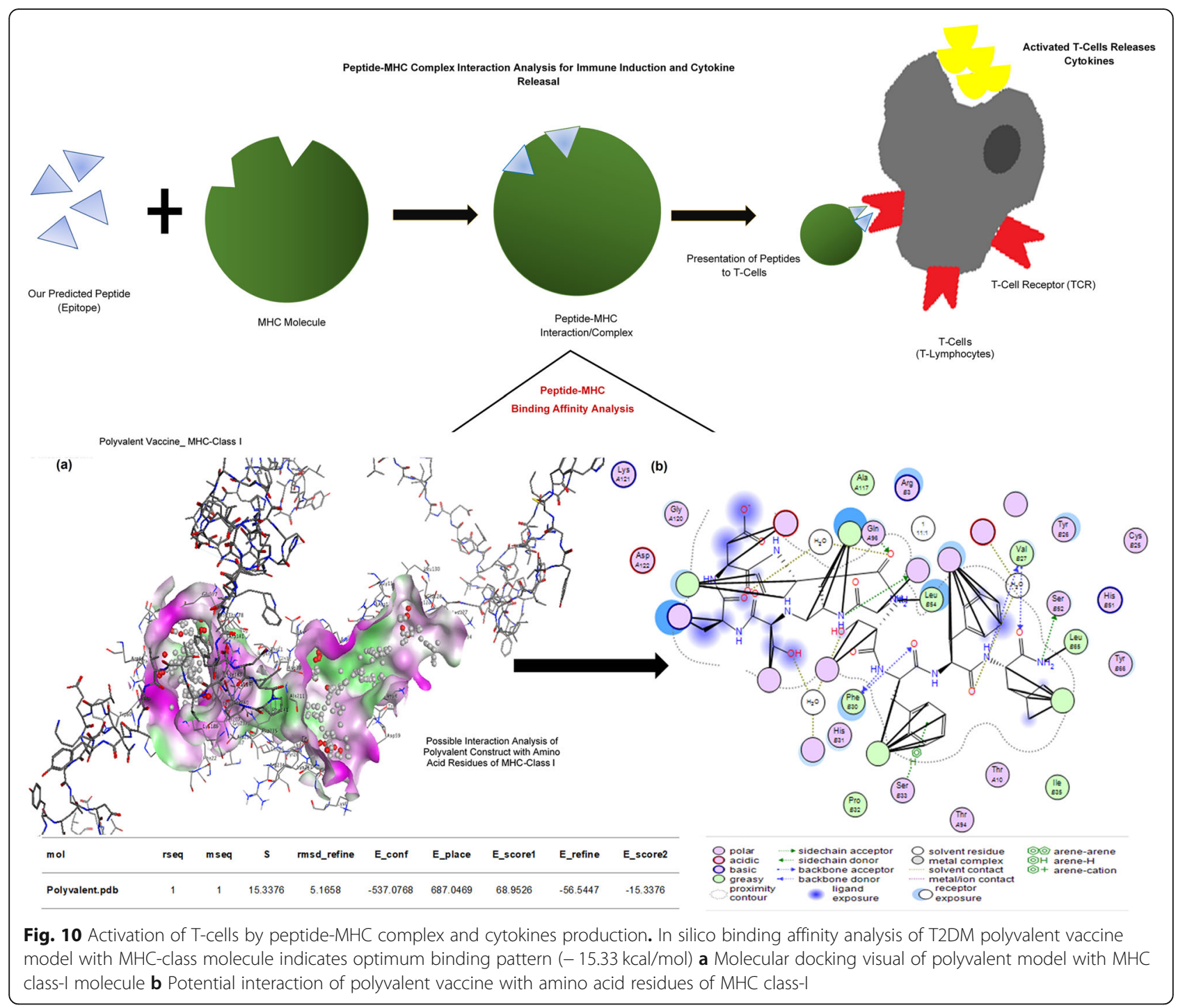

integrated immunoinformatic framework would strengthen the therapeutic discoveries and improve the treatment options to manage type 2 diabetes mellitus.

\section{Supplementary information}

Supplementary information accompanies this paper at https://doi.org/10. 1186/s12860-020-00279-w.

\section{Additional file 1.}

Additional file 2.

Authors' contributions

$\mathrm{AH}, \mathrm{ZS}$ and $\mathrm{MS}$ designed the study. $\mathrm{AH}$, and $\mathrm{ZS}$ performed the experiments. $\mathrm{CJ}, \mathrm{JM}, \mathrm{QZ}$, and MS analyzed and interpreted the data. AH, MS and MF wrote the manuscript. All the authors read and approved the final article.

\section{Funding}

Not applicable.
Availability of data and materials

The datasets generated during the current study have been included in manuscript and available as additional files.

Ethics approval and consent to participate Not applicable.

\section{Consent for publication}

Not applicable.

\section{Competing interests}

The authors declare that they have no competing interests.

\section{Author details}

'Institute of Molecular Biology and Biotechnology, Bahauddin Zakariya University Multan, Multan, Pakistan. ${ }^{2}$ The First Affiliated Hospital of Wenzhou Medical University, Wenzhou 325000, People's Republic of China. ${ }^{3}$ School of Pharmaceutical Sciences of Wenzhou Medical University, Wenzhou 325000, People's Republic of China. ${ }^{4}$ Informatics Institute, School of Medicine, The University of Alabama at Birmingham, Birmingham, AL, USA. ${ }^{5}$ Department of Hepatobiliary Surgery, The First Affiliated Hospital of Wenzhou Medical University, Wenzhou 325000, People's Republic of China. 
Received: 28 November 2019 Accepted: 28 April 2020

\section{Published online: 23 July 2020}

\section{References}

1. Zaccardi F, Webb DR, Yates T, Davies MJ. Pathophysiology of type 1 and type 2 diabetes mellitus: a 90-year perspective. Postgrad Med J. 2016;92:63-9.

2. Kahn $\mathrm{S}$. The relative contributions of insulin resistance and beta-cell dysfunction to the pathophysiology of type 2 diabetes. Diabetologia. 2003 46:3-19.

3. Ufuoma C, Ngozi JC, Kester AD, Godwin YD. Prevalence and risk factors of microalbuminuria among type 2 diabetes mellitus: a hospital-based study from, Warri, Nigeria. Sahel Med J. 2016;19:16.

4. Kumar KP, Ghosh S, Canovatchel W, Garodia N, Rajashekar S. A review of clinical efficacy and safety of canagliflozin $300 \mathrm{mg}$ in the management of patients with type 2 diabetes mellitus. Indian J Endocrinol Metab. 2017;21: 196.

5. Zghebi SS, Steinke DT, Carr MJ, Rutter MK, Emsley RA, Ashcroft DM. Examining trends in type 2 diabetes incidence, prevalence and mortality in the UK between 2004 and 2014. Diabetes Obes Metab. 2017;19:1537-45.

6. Zhou T, Meng X, Che H, Shen N, Xiao D, Song X, et al. Regulation of insulin resistance by multiple MiRNAs via targeting the GLUT4 signalling pathway. Cell Physiol Biochem. 2016;38:2063-78.

7. Mackenzie RW, Elliott BT. Akt/PKB activation and insulin signaling: a novel insulin signaling pathway in the treatment of type 2 diabetes. Diabetes Metab Syndr Obes. 2014;7:55.

8. Eriksson J, Koranyi L, Bourey R, Schalin-Jäntti C, Widen E, Mueckler M, et al. Insulin resistance in type 2 (non-insulin-dependent) diabetic patients and their relatives is not associated with a defect in the expression of the insulin-responsive glucose transporter (GLUT-4) gene in human skeletal muscle. Diabetologia. 1992;35:143-7.

9. García-Cáceres C, Quarta C, Varela L, Gao Y, Gruber T, Legutko B, et al. Astrocytic insulin signaling couples brain glucose uptake with nutrient availability. Cell. 2016;166:867-80.

10. Buck MD, O'Sullivan D, Pearce EL. T cell metabolism drives immunity. J Exp Med. 2015;212:1345-60.

11. Kaech SM, Cui W. Transcriptional control of effector and memory CD8+ T cell differentiation. Nat Rev Immunol. 2012:12:749.

12. Kehrl JH, Wakefield LM, Roberts AB, Jakowlew S, Alvarez-Mon M, Derynck R, et al. Production of transforming growth factor beta by human $T$ lymphocytes and its potential role in the regulation of T cell growth. J Exp Med. 1986;163:1037-50.

13. He Q. Yang Q-c, Zhou Q, Zhu H, Niu W-y, Feng J, et al. effects of varying degrees of intermittent hypoxia on proinflammatory cytokines and adipokines in rats and 3T3-L1 adipocytes. PLoS One. 2014;9:e86326.

14. Lüscher BP, Marini C, Joerger-Messerli MS, Huang X, Hediger MA, Albrecht C, et al. Placental glucose transporter (GLUT)-1 is down-regulated in preeclampsia. Placenta. 2017;55:94-9.

15. Macintyre AN, Gerriets VA, Nichols AG, Michalek RD, Rudolph MC, Deoliveira $D$, et al. The glucose transporter Glut1 is selectively essential for CD4 T cell activation and effector function. Cell Metab. 2014;20:61-72.

16. Yamagata AS, Mansur RB, Rizzo LB, Rosenstock T, Mclntyre RS, Brietzke E. Selfish brain and selfish immune system interplay: a theoretical framework for metabolic comorbidities of mood disorders. Neurosci Biobehav Rev. 2017;72:43-9.

17. Maclver NJ, Jacobs SR, Wieman HL, Wofford JA, Coloff UL, Rathmell JC Glucose metabolism in lymphocytes is a regulated process with significant effects on immune cell function and survival. J Leukoc Biol. 2008;84:949-57.

18. Yang Z, Yang J, Liu W, Wu L, Xing L, Wang Y, et al. T2D@ ZJU: a knowledgebase integrating heterogeneous connections associated with type 2 diabetes mellitus. Database. 2013;2013.

19. Gopinath K, Jayakumararaj R, Karthikeyan M. DAPD: a knowledgebase for diabetes associated proteins. IEEE/ACM Trans Comput Biol Bioinform. 2015 12:604-10.

20. Gupta S, Kapoor P, Chaudhary K, Gautam A, Kumar R, Open Source Drug Discovery Consortium, et al. In Silico approach for predicting toxicity of peptides and proteins. Plos One. 2013:8(9):e73957.

21. Islam SMA, Sajed T, Kearney CM, Baker EJ. PredSTP: a highly accurate SVM based model to predict sequential cystine stabilized peptides. BMC Bioinform. 2015;16:210.

22. UniProt CT. UniProt: the universal protein knowledgebase. Nucleic Acids Res. 2018:46:2699.
23. Kayatekin C, Amasino A, Gaglia G, Flannick J, Bonner JM, Fanning S, et al. Translocon Declogger Ste24 protects against IAPP oligomer-induced Proteotoxicity. Cell. 2018;173:62-73.

24. Gasteiger E, Hoogland C, Gattiker A, Wilkins MR, Appel RD, Bairoch A Protein identification and analysis tools on the ExPASy server. In: Walker JM, editor. The proteomics protocols handbook. Totowa: Springer; 2005. p. 571607.

25. Yu CS, Lin CJ, Hwang JK. Predicting subcellular localization of proteins for gram-negative bacteria by support vector machines based on n-peptide compositions. Protein Sci. 2004;13:1402-6.

26. Van Zundert G, Rodrigues J, Trellet M, Schmitz C, Kastritis P, Karaca E, et al The HADDOCK2. 2 web server: user-friendly integrative modeling of biomolecular complexes. J Mol Biol. 2016:428:720-5.

27. Nielsen M, Lundegaard C, Lund $O$, Keşmir C. The role of the proteasome in generating cytotoxic T-cell epitopes: insights obtained from improved predictions of proteasomal cleavage. Immunogenetics. 2005;57:33-41.

28. Bui H-H, Sidney J, Li W, Fusseder N, Sette A. Development of an epitope conservancy analysis tool to facilitate the design of epitope-based diagnostics and vaccines. BMC Bioinform. 2007:8:361.

29. Camproux A-C, Gautier R, Tuffery P. A hidden markov model derived structural alphabet for proteins. J Mol Biol. 2004:339:591-605.

30. Hornung V, Ablasser A, Charrel-Dennis M, Bauernfeind F, Horvath G, Caffrey DR, et al. AIM2 recognizes cytosolic dsDNA and forms a caspase-1-activating inflammasome with ASC. Nature. 2009;458:514.

31. Chen JY, Pandey R, Nguyen TM. HAPPI-2: a comprehensive and high-quality map of human annotated and predicted protein interactions. BMC Genomics. 2017;18:182.

32. Szklarczyk D, Morris JH, Cook H, Kuhn M, Wyder S, Simonovic M, et al. The STRING database in 2017: quality-controlled protein-protein association networks, made broadly accessible. Nucleic Acids Res. 2016:45:D362-D8.

33. Shannon P, Markiel A, Ozier O, Baliga NS, Wang JT, Ramage D, et al. Cytoscape: a software environment for integrated models of biomolecular interaction networks. Genome Res. 2003;13:2498-504.

34. Zhang Y. I-TASSER server for protein 3D structure prediction. BMC Bioinform. 2008;9:40

35. Roy A, Kucukural A, Zhang Y. I-TASSER: a unified platform for automated protein structure and function prediction. Nat Protoc. 2010;5:725.

36. Yang J, Yan R, Roy A, Xu D, Poisson J, Zhang Y. The I-TASSER suite: protein structure and function prediction. Nat Methods. 2015;12:7.

37. Pettersen EF, Goddard TD, Huang CC, Couch GS, Greenblatt DM, Meng EC et al. UCSF chimera-a visualization system for exploratory research and analysis. J Comput Chem. 2004;25:1605-12.

38. Pathan M, Keerthikumar S, Chisanga D, Alessandro R, Ang C-S, Askenase P, et al. A novel community driven software for functional enrichment analysis of extracellular vesicles data. J Extracell. 2017:6:1321455.

39. Colovos C, Yeates TO. Verification of protein structures: patterns of nonbonded atomic interactions. Protein Sci. 1993:2:1511-9.

40. Benkert P, Tosatto SC, Schomburg D. QMEAN: a comprehensive scoring function for model quality assessment. Proteins: Structure Funct Bioinform. 2008;71:261-77.

41. Studer G, Biasini M, Schwede T. Assessing the local structural quality of transmembrane protein models using statistical potentials (QMEANBrane). Bioinformatics. 2014;30:i505-i11.

42. Lovell SC, Davis IW, Arendall WB, De Bakker PI, Word JM, Prisant MG, et al. Structure validation by $C a$ geometry: $\varphi, \psi$ and $C \beta$ deviation. Proteins: Structure Funct Bioinform. 2003;50:437-50.

43. Bhattacharya D, Nowotny J, Cao R, Cheng J. 3Drefine: an interactive web server for efficient protein structure refinement. Nucleic Acids Res. 2016;44 W406-W9.

44. Bhattacharya $D$, Cheng J. i3Drefine software for protein 3D structure refinement and its assessment in CASP10. PLoS One. 2013;8:e69648.

45. Bhattacharya $D$, Cheng J. 3Drefine: consistent protein structure refinement by optimizing hydrogen bonding network and atomic-level energy minimization. Proteins: Structure Funct Bioinform. 2013:81:119-31.

46. Cheng J, Randall AZ, Sweredoski MJ, Baldi P. SCRATCH: a protein structure and structural feature prediction server. Nucleic Acids Res. 2005;33:W72-W6.

47. Doytchinova IA, Flower DR. VaxiJen: a server for prediction of protective antigens, tumour antigens and subunit vaccines. BMC Bioinform. 2007;8:4.

48. Doytchinova IA, Flower DR. Identifying candidate subunit vaccines using an alignment-independent method based on principal amino acid properties. Vaccine. 2007;25:856-66. 
49. Doytchinova IA, Flower DR. Bioinformatic approach for identifying parasite and fungal candidate subunit vaccines. Open Vaccine J. 2008;1:4.

50. Bjellqvist B, Hughes GJ, Pasquali C, Paquet N, Ravier F, Sanchez JC, et al. The focusing positions of polypeptides in immobilized $\mathrm{pH}$ gradients can be predicted from their amino acid sequences. Electrophoresis. 1993;14:102331.

51. Nezafat N, Ghasemi Y, Javadi G, Khoshnoud MJ, Omidinia E. A novel multiepitope peptide vaccine against cancer: an in silico approach. J Theor Biol. 2014;349:121-34.

52. Cnop M, Welsh N, Jonas J-C, Jörns A, Lenzen S, Eizirik DL. Mechanisms of pancreatic $\beta$-cell death in type 1 and type 2 diabetes: many differences, few similarities. Diabetes. 2005;54:S97-S107.

53. Spohn G, Schori C, Keller I, Sladko K, Sina C, Guler R, et al. Preclinical efficacy and safety of an anti-IL-1 $\beta$ vaccine for the treatment of type 2 diabetes. Mol Ther-Meth Clin D. 2014;1:140-8.

54. Kahn SE, Cooper ME, Del Prato S. Pathophysiology and treatment of type 2 diabetes: perspectives on the past, present, and future. Lancet. 2014;383 1068-83.

55. Zhang Y, Yu X-L, Zha J, Mao L-Z, Chai J-Q, Liu R-T. Therapeutic vaccine against IL-1 $\beta$ improved glucose control in a mouse model of type 2 diabetes. Life Sci. 2018;192:68-74.

56. Herder C, Dalmas E, Böni-Schnetzler M, Donath MY. The IL-1 pathway in type 2 diabetes and cardiovascular complications. Trends Endocrinol Metab. 2015;26:551-63.

57. Ludvigsson J, Faresjö M, Hjorth M, Axelsson S, Chéramy M, Pihl M, et al. GAD treatment and insulin secretion in recent-onset type 1 diabetes. $\mathrm{N}$ Engl J Med. 2008:359:1909-20.

58. Cook DP, Gysemans C, Mathieu C. Prospects of a type 1 diabetes vaccine. Expert Opin Biol Ther. 2017;17:403-6.

59. Wofford JA, Wieman HL, Jacobs SR, Zhao Y, Rathmell JC. IL-7 promotes Glut1 trafficking and glucose uptake via STAT5-mediated activation of Akt to support T-cell survival. Blood. 2008;111:2101-11.

60. Islam S, Mir AR, Arfat MY, Alam K, Ali A. Studies on glycoxidatively modified human lgG: implications in immuno-pathology of type 2 diabetes mellitus. Int J Biol Macromol. 2017;104:19-29.

61. Freemerman AJ, Johnson AR, Sacks GN, Milner JJ, Kirk EL, Troester MA, et al. Metabolic reprogramming of macrophages glucose transporter 1 (GLUT1)mediated glucose metabolism drives a proinflammatory phenotype. J Biol Chem. 2014;289:7884-96.

62. Wieman HL, Wofford JA, Rathmell JC. Cytokine stimulation promotes glucose uptake via phosphatidylinositol-3 kinase/Akt regulation of Glut1 activity and trafficking. Mol Biol Cell. 2007;18:1437-46.

63. Shikhman AR, Brinson DC, Valbracht J, Lotz MK. Cytokine regulation of facilitated glucose transport in human articular chondrocytes. J Immunol. 2001;167:7001-8.

64. Bédard S, Marcotte B, Marette A. Cytokines modulate glucose transport in skeletal muscle by inducing the expression of inducible nitric oxide synthase. Biochem J. 1997;325:487-93.

65. Pickup JC, Chusney GD, Thomas SM, Burt D. Plasma interleukin-6, tumour necrosis factor $a$ and blood cytokine production in type 2 diabetes. Life Sci. 2000;67:291-300

66. Frauwirth KA, Riley JL, Harris MH, Parry RV, Rathmell JC, Plas DR, et al. The CD28 signaling pathway regulates glucose metabolism. Immunity. 2002;16: 769-77.

67. Stephens JM, Carter BZ, Pekala P, Malter J. Tumor necrosis factor alphainduced glucose transporter (GLUT-1) mRNA stabilization in 3T3-L1 preadipocytes. Regulation by the adenosine-uridine binding factor. J Biol Chem. 1992;267:8336-41.

68. King BC, Esquerra JL, Golec E, Eliasson L, Kemper C, Blom AM. CD46 activation regulates miR-150-mediated control of GLUT1 expression and cytokine secretion in human CD4+ T cells. J Immunol. 2016;196: $1636-45$.

69. Dhanda SK, Usmani SS, Agrawal P, Nagpal G, Gautam A, Raghava GPS. Novel in silico tools for designing peptide-based subunit vaccines and Immunotherapeutics. Brief Bioinformat. 2017;2017(18):467-78.

70. Lu K, Su B, Meng X. Recent advances in the development of vaccines for diabetes, hypertension, and atherosclerosis. J Diabetes Res. 2018;24:1638462.

71. Monteiro MP. Obesity vaccines. Hum Vaccin Immunother. 2014;10:887-95.

72. Zha J, Chi XW, Yu XL, et al. Interleukin-1ß-targeted vaccine improves glucose control and $\beta$-cell function in a diabetic KK-ay mouse model. PLoS One. 2016;11:e0154298.
73. Cavelti-Weder C, Timper K, Seelig E, et al. Development of an interleukin-1 $\beta$ vaccine in patients with type 2 diabetes. Molecular Ther. 2016;24:1003-12.

74. Cornell S. Differentiating among incretin therapies: a multiple-target approach to type 2 diabetes. J Clin Pharm Ther. 2012;37:510-24.

75. Pang Z, Nakagami H, Osako MK, et al. Therapeutic vaccine against DPP4 improves glucose metabolism in mice. Proceed Nat Aca Sci Uni Stat Amer. 2014;111:E1256-63.

76. Hasan M, Islam MS, Chakraborty S, Mustafa AH, Azim KF, Joy ZF, et al. Contriving a chimeric polyvalent vaccine to prevent infections caused by herpes simplex virus (Type-1 and Type-2): an exploratory immunoinformatic approach. J Biomol Struct Dyn. 2019;12:1-18.

\section{Publisher's Note}

Springer Nature remains neutral with regard to jurisdictional claims in published maps and institutional affiliations.
Ready to submit your research? Choose BMC and benefit from:

- fast, convenient online submission

- thorough peer review by experienced researchers in your field

- rapid publication on acceptance

- support for research data, including large and complex data types

- gold Open Access which fosters wider collaboration and increased citations

- maximum visibility for your research: over $100 \mathrm{M}$ website views per year

At BMC, research is always in progress.

Learn more biomedcentral.com/submissions 